\title{
The puzzling uniqueness of the heterotrimeric G15 protein and its potential beyond hematopoiesis
}

\author{
Flavia Giannone, Giorgio Malpeli ${ }^{2}$, Veronica Lisi ${ }^{1}$, Silvia Grasso ${ }^{3}$, Priyanka Shukla ${ }^{3}$, \\ Dunia Ramarli ${ }^{3}$, Silvia Sartoris ${ }^{3}$, Vladia Monsurró ${ }^{3}$, Mauro Krampera1, Eliana Amato ${ }^{2}$, \\ Giuseppe Tridente $^{3}$, Marco Colombatti ${ }^{3}$, Marco Parenti and Giulio Innamorati ${ }^{3}$ \\ Department of Experimental Medicine, University of Milano-Bicocca, Monza 20052, Italy \\ ${ }^{1}$ Section of Hematology, Department of Clinical and Experimental Medicine, ${ }^{2}$ Section of Anatomic Pathology, Department of Pathology and ${ }^{3}$ Section of Immunology, \\ Department of Pathology, University of Verona, Verona 37134, Italy
}

(Correspondence should be addressed to G Innamorati; Email: giulio.innamorati@ univr.it)

\begin{abstract}
Heterotrimeric $G$ proteins transduce the signals of the largest family of membrane receptors (G protein-coupled receptors, GPCRs) hence triggering the activation of a wide variety of physiological responses. $\mathrm{G} 15$ is a $\mathrm{G}$ protein characterized by a number of functional peculiarities that make its signaling exceptional: 1) it can couple a variety of Gs-, Gi/o-, and Gq-linked receptors to phospholipase $\mathrm{C}$ activation; 2) relatively to other $\mathrm{G}$ proteins, it is poorly affected by $\beta$-arrestin-dependent desensitization, the general mechanism that regulates GPCR function and 3 ) at the protein level, its expression is only detected in highly specific cell types (hematopoietic and epithelial cells). G15 $\alpha$-subunit displays unique structural and biochemical properties, and is phylogenetically the most recent and divergent component of the $\mathrm{G} \alpha \mathrm{q} / 11$ subfamily. All these aspects shed a mysterious light on $\mathrm{G} 15$ biological role, which remains substantially elusive. Thus, far, G15 signaling has been analyzed in the context of hematopoiesis. Here, we highlight observations supporting the view that G15 functions may extend further beyond the immune system. In addition, we describe puzzling aspects of G15 signaling that offer a novel perspective in the understanding of its physiological role.
\end{abstract}

Journal of Molecular Endocrinology (2010) 44, 259-269

\section{Introduction}

The $\alpha$-subunit of the heterotrimeric G15 protein $(\mathrm{G} \alpha 15)$ is the most divergent member of the Gaq family sharing 57\% amino acid sequence identity with $\mathrm{G} \alpha \mathrm{q}$ (for a sequence alignment see Hubbard \& Hepler (2006)). Ga15 was originally cloned in mouse (Wilkie et al. 1991). The human isoform was named Ga16 assuming it represented a novel subtype (Amatruda et al. 1991), but later on it was recognized as the poorly conserved ortholog of $\mathrm{G} \alpha 15$ sharing only $85 \%$ sequence identity.

G15 is best known for its ability to create a functional link between hundreds of different $\mathrm{G}$ protein-coupled receptors (GPCRs) and the $\beta$ isoform of phospholipase C (PLCB; Milligan et al. 1996). For this reason, G15 has often served as a versatile readout, particularly, in the preliminary characterization of orphan GPCRs when the lack of an agonist precludes any functional characterization of the downstream signaling pathway (and vice versa). Powerful cellular platforms for the screening of specific ligands have been created by co-expressing G15 together with orphan GPCRs. Furthermore, thanks to G15, it was confirmed that unconventional GPCRs like OA1 (Innamorati et al. 2006) and smoothened (Masdeu et al. 2006) are indeed $\mathrm{G}$ protein-coupled.

Despite the restricted expression profile (Table 1) and the great success as a pharmacological tool, a number of gene knockout studies (in animal or cellular models) revealed relatively little about G15 physiological activity (see below). Part of the mystery surrounding the role of this G protein may derive from assumptions drawn perhaps too prematurely after the cloning, such as an exclusive link with hematopoiesis.

DOI: 10.1677/JME-09-0134 Online version via http://www.endocrinology-journals.org 
Table 1 List of organs and cells from various organisms showing G $\alpha 15$ expression according to literature data

\begin{tabular}{|c|c|c|c|c|}
\hline & Species & References & EST $(\mathrm{m})$ & EST $(H)$ \\
\hline \multicolumn{5}{|l|}{ Organ, cells } \\
\hline \multicolumn{5}{|l|}{ Immune system } \\
\hline Thymus (decreasing in adult) & $\mathrm{m}$ & Wilkie et al. (1991) & ++ & ++++ \\
\hline Lymph nodes & $\mathrm{m}$ & Davignon et al. (2000) & - & 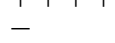 \\
\hline Blood & & & - & +++ \\
\hline Pre-B cells & $\mathrm{H}$ & $\begin{array}{l}\text { Mapara et al. (1995) and } \\
\text { Grant et al. (1997) }\end{array}$ & & \\
\hline HSC & $\mathrm{H}$ & Lippert et al. (1997) & & \\
\hline$\gamma \delta$ & $\mathrm{H}$ & Lippert et al. (1997) & & \\
\hline Activated T cells & $\mathrm{H}$ & Lippert et al. (1997) & & \\
\hline Megakaryocytes & $\mathrm{H}$ & den Dekker et al. (2001b) & & \\
\hline Bone marrow: HSC and erythroid cells & $\mathrm{H}$ & $\begin{array}{l}\text { Tenailleau et al. (1997) and } \\
\text { Pfeilstocker et al. (2000) }\end{array}$ & ++++ & ++ \\
\hline \multicolumn{5}{|c|}{ 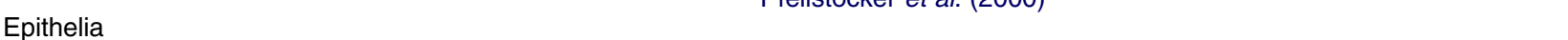 } \\
\hline Hair follicle & $\mathrm{b}$ & Wilkie et al. (1991) & & \\
\hline Skin: keratinocytes & $\mathrm{b}$ & Rock et al. (1997) & +++ & + \\
\hline Tongue: taste bud & r & Kusakabe et al. (1998) & - & +++ \\
\hline Thymus: epithelial cells & $\mathrm{H}$ & Fig. 2, this review & & \\
\hline \multicolumn{5}{|l|}{ Other organs } \\
\hline Brain (traces) & $\mathrm{m}$ & Wilkie et al. (1991) & + & + \\
\hline Heart (traces) & $\mathrm{m}$ & Wilkie et al. (1991) & +++ & - \\
\hline Lungs (traces) & $\mathrm{m}$ & Wilkie et al. (1991) & - & ++ \\
\hline Kidney (traces) & $\mathrm{m}$ & Wilkie et al. (1991) & - & + \\
\hline
\end{tabular}

$\mathrm{H}$, human; $b$, baboon; $\mathrm{m}$, mouse; $\mathrm{r}$, rat.

"Traces" reported in parenthesis means that mRNA expression is low and the protein is undetectable by immunoblotting. Other tissues where reported as substantially negative: yalk $(\mathrm{m})$, uterus $(\mathrm{m})$, testis $(\mathrm{m})$, liver $(\mathrm{m}, \mathrm{H})$ (Fig. 2) (Wilkie et al. (1991)). In the last two columns the approximate expression patterns inferred from EST sources as reported by UniGene (NCBI). Reference numbers are Hs.73797 and Mm.1546 for human and mouse respectively. Symbols are present when data are available and refer to the number of transcripts per million of ESTs $(-$, absent;,$+ 1-9$ copies;,$++ 10-29$ copies;,$+++ 30-99$ copies; ++++ , more than 100 copies).

\section{The evasive nature of $\mathrm{G} \propto 15$ expression}

\section{G $\alpha 15$ distribution profile}

\section{Hematopoiesis}

In the original characterization, the murine G $\alpha 15$ was found to be selectively expressed by hematopoietic cells and therefore in the bone marrow, thymus (where it declines in the adult), spleen, and embryonic liver (Amatruda et al. 1991, Wilkie et al. 1991). Consequently, a wealth of attention was focused on early maturation stages of hematopoiesis (Hubbard \& Hepler 2006, Su et al. 2009) such as cluster of differentiation 34 (CD34) positive hematopoietic stem cells (HSCs; Tenailleau et al. 1997, Pfeilstocker et al. 2000), erythroid precursors (Ghose et al. 1999), megakaryocytic (den Dekker et al. 2001a,b), and B cells progenitors (Mapara et al. 1995). The expression of G $\alpha 15$ is subsequently lost upon cell maturation. This was reproduced in vitro using inducible cellular models, such as HL60 or WB4 cells
(Amatruda et al. 1991, Grant et al. 1997, Tenailleau et al. 1997), where the protein expression progressively declines upon acquisition of a neutrophil-like phenotype. On the other hand, G $\alpha 15$ expression may be transiently restored by committed hematopoietic cells upon specific stimulation, as shown by activating quiescent T cells with Leuco A (Lippert et al. 1997).

Based on data collected in four different cell lines, Wilkie et al. (1991) concluded that G $\alpha 15$ is absent in stromal cells lines. In good agreement, we found only minimal mRNA traces, and no corresponding protein signal in mesenchymal stem cells from bone marrow or thymic stromal cells, either freshly isolated or cultured, were found (Fig. 1A and B). It appears therefore that, besides HSCs, other stem cells including more immature stages like embryonic stem cells and yolk do not express Ga15 (Wilkie et al. 1991). In summary, G15 expression cannot be generalized to all stem cells, but overlaps with the CD34 marker for stem and progenitor cell population (Pfeilstöcker et al. 1998, 2000). 


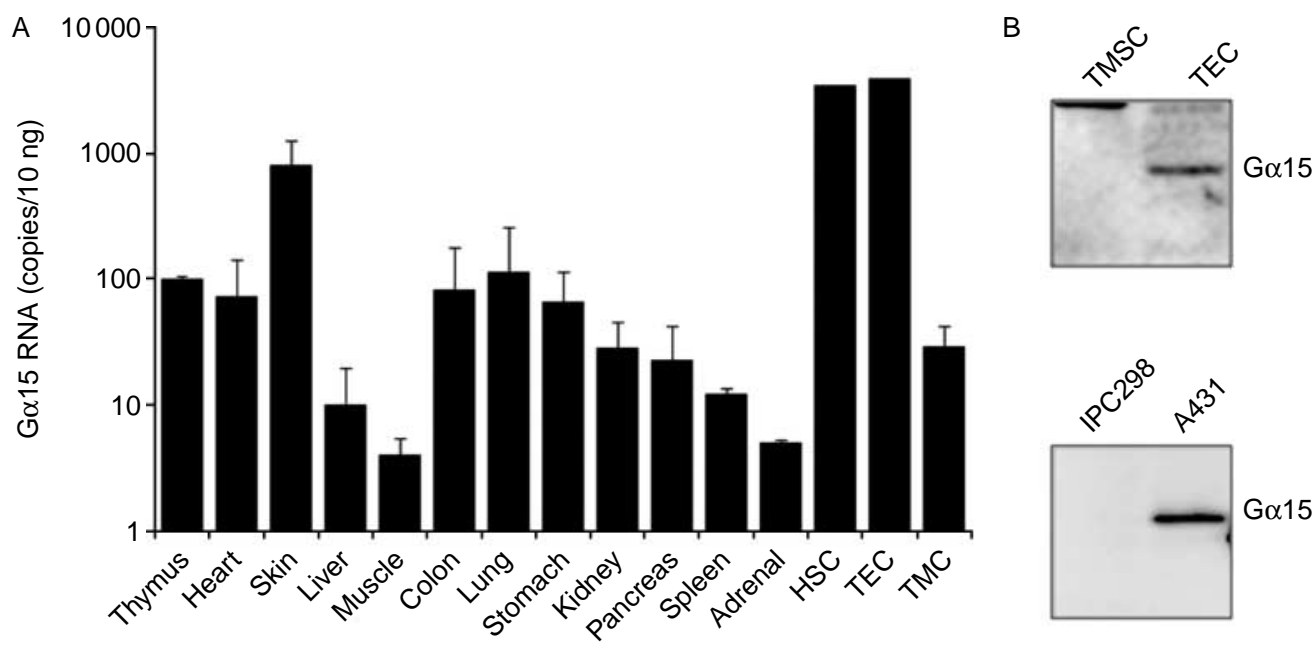

C

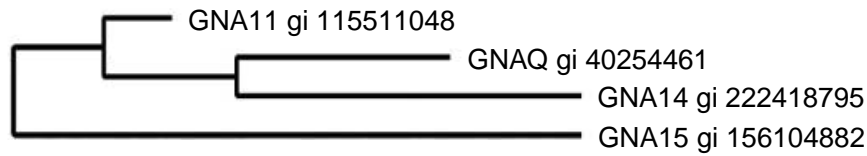

Figure $1 \mathrm{G} \alpha 15$ expression in human tissues and cells as assessed by quantitative RT-PCR (A) or immunoblotting (B). HSC is for hematopoietic stem cells, TEC for thymic epithelial cells, TMSC for mesenchymal stem cells. (A) GNA15 (G $\alpha 15$ gene) expression analysis was performed by quantitative RT-PCR using the TaqMan assay Hs_00157720_m1 (Applied Biosystems). As an endogenous reference, glyceraldehyde-3-phosphate dehydrogenase transcript level was measured in parallel. GNA15 copy number (means of three measures \pm S.D.) was assessed by the standard curve method, according to Lai et al. (2003). (B) Immunoblotting detected a positive signal in TEC, consistent with the robust $\mathrm{G} \alpha 15$ mRNA presence, while TMSC resulted negative. G $\alpha 15$ was also present in the epithelioid cell line A413 as opposite to the melanoma cell line IPC298. (C) Phylogenetic tree of Gaq/11 family members obtained at http://www.phylogeny.fr, according to Dereeper et al. (2008). GNA15 appears as the most distant member within the Gaq family.

\section{Epithelia}

Despite broadly described as hematopoietic specific (Amatruda et al. 1991, Hubbard \& Hepler 2006, Su et al. 2009), G15 expression was occasionally reported in tissues that are not part of the immune system, particularly in a variety of epithelia. While analyzing baboon skin by in situ hybridization, Rock et al. (1997) reported the presence of $\mathrm{G} \alpha 15$ in hair follicular epithelium. In the hair follicle bulge of murine skin (Shi et al. 2003) reside CD34-positive cells that may serve as a reservoir for Langerhans cells as well as for other immune cell precursors (Gilliam et al. 1998, Kumamoto et al. 2003). The existence of a population of slowly cycling immature cells originated from hematopoietic precursors could thus explain the presence of G $\alpha 15$ signal. On the other hand, CD34 was also specifically associated with keratinocyte stem cells characterized by high in vitro clonogenic potential (Trempus et al. 2003), and Ga15 mRNA was found in cultured human keratinocytes from neonatal foreskin (that originate from ectoderm rather than mesoderm) but not in fibroblasts, melanocytes, or endothelial cells (Rock et al. 1997). Consistent with this finding, we report robust expression in the skin and in the epidermoid A431 cell line (Fig. 1). Furthermore, northern blot analysis detected G $\alpha 15$ mRNA in rat tongue epithelia (Kusakabe et al. 1998).

Since mature cutaneous epithelium is maintained by an unknown number of progenitor populations (Yan \& Owens 2008), it would be interesting to define in deeper details the cellular localization of $\mathrm{G} \alpha 15$ in these tissues.

Consistent with an expression profile extended to epithelial cells, transcriptional levels comparable to HSCs are reached in cells of an internal epithelium, namely thymic epithelial cells (TECs, Fig. 1). By contrast, mesenchymal stem cells derived from the same organ resulted negative.

HSCs, TECs, and progenitor cells in epidermis share functional and phenotypic characteristics. For instance, epidermal keratinocytes can recruit hematopoietic precursors and support the development of a thymic microenvironment (Clark et al. 2005). Thus, one could wonder whether a common functional signature links these cell types to the expression of G $\alpha 15$. A very intriguing possibility is that $\mathrm{G} \alpha 15$ is expressed at intermediate stages of maturation, when cells are in the process of leaving quiescence to generate lineages that can be stimulated to rapid proliferation. If demonstrated, this aspect could be relevant in pathological processes. Although there is no direct 
indication pointing to an involvement of G15 in tumor cell growth (Heasley et al. 1996b), Ga15 was coimmunoprecipitated to the M1 muscarinic receptor in prostate adenoma (Ruggieri et al. 1995, Luthin et al. 1997). Normal tissue was not analyzed, but we found the immunoblot of healthy prostate negative for $\mathrm{G} \alpha 15$ expression thus suggesting that its appearance may relate to initial phases of the transformation process.

\section{Or elsewhere?}

By performing Southern blotting analysis of PCR products, Wilkie et al. (1991) showed a weak G $\alpha 15$ expression in several organs. We confirmed by quantitative PCR (Fig. 1A) that very low, albeit significant, levels of $\mathrm{G} \alpha 15$ are present in heart, kidney, and almost all tissues analyzed. Though abundance was much reduced compared with HSCs or TECs, a small number of G $\alpha 15$ mRNA copies are therefore present in most tissues, nonetheless the translational level remains below the detection limit of the antibodies available for immunoblotting (estimated as < $1 \mathrm{ng}$ in HeLa cells (Krumins \& Gilman 2006)). An antibody suitable for immunohistochemistry would allow analyzing different epithelia present in various organs and pinpoint positive cell lineages. Unfortunately, a similar tool has not yet been described in the literature, possibly because of the limited choice of epitopes presenting specific immunogenicity without cross-reaction with other members of the $\mathrm{Gq} / 11$ protein subfamily members.

Under these circumstances, there is a strong possibility that small subpopulations of cells derived from specialized epithelia may contribute the low signal detected in most human organs.

\section{Two Ga15 isoforms?}

Another puzzling aspect about Ga15 expression is that, in addition to the most commonly observed $43 \mathrm{kDa}$ form, a $46 \mathrm{kDa}$ form was repeatedly described (Lippert et al. 1997, Tenailleau et al. 1997, den Dekker et al. 2001a,b). During megakaryocytic maturation (den Dekker et al. 2001 a,b) and T lymphocyte activation, the transient appearance of the heavier band anticipates the similarly transient expression of the $43 \mathrm{kDa}$ form (Lippert et al. 1997). The downmodulation of both forms by five specific shRNA sequences (G Innamorati 2009, unpublished observation) proves that both represent $\mathrm{G} \alpha 15$ rather than a cross-reacting $\alpha$-subunit, or any other protein sharing a common epitope.

For other $\mathrm{G}$ protein $\alpha$-subunits, alternative splicing causes the appearance of similar doublets in acrylamide gels (Robishaw et al. 1986, Tsukamoto et al. 1991). However, in the case of $\mathrm{G} \alpha 15$, neither protein kinase C (PKC) phosphorylation (Gu et al. 2003) nor cysteine palmitoylation at position 9 and 10 of the amino-terminus (Pedone \& Hepler 2007) significantly affected the migration of the recombinant protein. The main gene transcript (NM_002068) of human GNA15 (the gene encoding for $\mathrm{G} \alpha 15$ ) consists of seven exons. An alternative splice variant (AK300481) was found in NCBI database by SpliceMiner software (Kahn et al. 2007), however, this mRNA variant contains the first two and a larger third exon that are not compatible with the $46 \mathrm{kDa}$ protein.

Further investigation is needed to unravel the molecular details that differentiate these two species and to verify if they fulfill specific roles.

\section{The evasive nature of G15 coupling}

G15 coupling to GPCRs appears as characterized by low selectivity but high efficiency.

\section{G15 promiscuity and its physiological coupling}

Many authors documented the peculiar promiscuity of G15 by showing functional interactions with a wide variety of different receptors in a large number of transfected cell lines (Offermanns \& Simon 1995, Zhu \& Birnbaumer 1996). Such versatility would predict that dozens of different GPCRs expressed by any given cell (Hakak et al. 2003) may act as physiological upstream activators of G15. In addition to various chemokine receptors, HSCs express other GPCRs such as the B2AR (Muthu et al. 2007), opioid receptors (Rozenfeld-Granot et al. 2002) and smoothened receptors (Masdeu et al. 2006). Needless to say, these receptors were proved to be good couplers of G15 in recombinant systems (Offermanns \& Simon 1995, Wu et al. 1995, Zhu \& Birnbaumer 1996, Lee et al. 1998, Gutierrez-Frias et al. 2004).

However, promiscuity remains to be demonstrated under naive conditions. The identification of specific receptor-G15 interactions represents a very challenging task as PLC is also activated by the ubiquitous $\mathrm{Gq} / 11$ or by other $\mathrm{G}$ proteins via release of $\beta \gamma$-subunit, or by indirect activation through other intermediate effectors (see for instance the activation of PLC $\varepsilon$ by Gs via PKA (Schmidt et al. 2001)). The lack of pharmacological inhibitors specific for $\mathrm{G} \alpha 15$ further complicates the analysis.

Thus, it is not surprising that only very few examples describe GPCR signaling through naive G15. Knocking out $\mathrm{G} \alpha 15$ expression in transgenic mice reduced the coupling of C5a to calcium release in macrophages while leaving intact the coupling to other GPCRs (Davignon et al. 2000), including P2Y2 receptor stimulated by UTP (Davignon et al. 2000). Surprisingly, in erythroleukemia cells, silencing $\mathrm{G} \alpha 15$ led to reduced mobilization of intracellular $\mathrm{Ca}^{2+}$ upon stimulation of 
the same P2Y2 purinoceptor (Baltensperger \& Porzig 1997). These results may be reconciled considering that cell-specific components contribute to define the specificity of receptor-G protein interaction (Ostrom $\&$ Insel 2004), and hence specialized cells may dictate specific coupling profiles.

Olfactory $\mathrm{G}$ proteins and transducins are exclusively expressed in sensory neurons to mediate the signaling of dedicated GPCRs (olfactory receptors and opsins respectively). Likewise, the selective expression of $\mathrm{G} \alpha 15$ in HSCs suggested that it may serve as a specific effector of GPCRs involved in immunity (Amatruda $e t$ al. 1993). In this context, sphingosine 1-phosphate receptor 4 (S1PR4) is a good candidate as a physiological activator of G15. The lymphoid tissue-specific S1PR4 is part of a family of receptors responding to lysophospholipids or lysosphingolipids (Rivera et al. 2008). It has been reported that the genes encoding for S1PR4 and GNA15 are located in tandem, likely under the control of the same promoter (Contos et al. 2002). Consistently, according to microarray data, both the genes are simultaneously expressed in mouse fetal liver cells, and are silenced during erythroid differentiation (A Ronchi, personal communication, 2007). An interaction between these two proteins could explain why, in the presence of S1P containing serum (Yatomi et al. 2001), the inhibition or downregulation of $\mathrm{G} \alpha 15$ affects erythroid cells growth and differentiation (Ghose et al. 1999). Nonetheless, when tested with GTP photoaffinity label in CHO cells (Graler et al. 2003), S1PR4 was shown to be coupled to Gi and G12/13 but not to Gq/11 and G15.

Another good candidate as a specific G15 activator would be CXCR4, the receptor responsible for retaining HSC in the bone marrow (Levesque \& Winkler 2008). Bafflingly, several chemokine receptors including CXCR4 (Wu et al. 1995, Arai \& Charo 1996) in addition to CCR5 (Tian et al. 2008), CCR7 (Tian et al. 2008), and CCR1 (Arai \& Charo 1996, Kuang et al. 1996) are among the very few GPCRs that refrain to couple with G15 upon exogenous expression. Again, the cellular context could make a difference since silencing G $\alpha 15$ mRNA in monocytic THP1 cells partially reduced chemotactic ability in response to CCR1 (Tian et al. 2008). Another exception to G15 promiscuity is CCR2A (Kuang et al. 1996, Tian et al. 2008), but not its splice variant CCR2B that only differs in the carboxylterminus. Yet, also CCR2A coupled to G15 when ectopically expressed in HEK-293 cells (Arai \& Charo 1996) instead of COS-7 cells. If the cellular context influences the specificity of the interaction, many molecular mechanisms could be involved. Although the GPCR carboxyl-terminus is not generally considered to directly determine $G$ protein specificity (G15 included), it could act indirectly by bridging GPCRs to preassembled signaling complexes. Likewise, post-translational modifications targeting the $\mathrm{G}$ protein to specific plasma membrane microdomains could physically restrict G15 interactions with GPCRs partitioned within these discrete areas. Another largely underestimated cause for coupling discrimination is the identity of the $\beta$ - and $\gamma$-subunits forming the heterotrimeric complex. Five $\beta$ - and twelve $\gamma$-subunits assemble in multiple combinations with the $\alpha$-subunit. If the composition of the heterotrimer narrows the number of upstream GPCR partners (Robillard et al. $2000)$, the cellular repertoire of $\beta$ - and $\gamma$-subunits (Kleuss et al. 1993) could be crucial to modulate specificity. In a similar manner, the formation of receptor heterodimers could provide an additional mechanism for discrimination (Maggio et al. 2007).

Discrepancies observed in different cellular systems are not unraveled by transgenic animal models that failed to provide a clear indication about which GPCRs are upstream G15. G $\alpha 15$ knockout mice display normal maturation of all cell lineages and mount a normal response to the immune challenges (Davignon et al. 2000). Unfortunately, very limited data are available in non-hematopoietic tissues. For instance, the increase of cGMP occurring upon activation of the muscarinic M3 receptor in membrane fractions of tracheal smooth muscle was inactivated by a G $\alpha 15$-specific antibody (Bruges et al. 2007). Expanding research focus beyond immunity could prove critical. In addition, newly emerged data suggest that G15 action may become particularly relevant under exceptional conditions, i.e. in the case of prolonged stimulation (see below).

\section{Differential sensitivity of G15 to receptor desensitization}

There is an additional feature that makes G15 different from other $\mathrm{G}$ proteins, i.e. its relatively enduring activity under conditions in which the coupling efficiency of other $\mathrm{G}$ proteins is reduced by GPCR desensitization. GPCR desensitization is a general regulatory mechanism operated by cytosolic adaptor proteins, named $\beta$-arrestins, that rapidly translocate to a hundred different GPCRs after agonist stimulation (DeWire et al. 2007). The term 'arrestin' derives from the proteins' ability to dampen receptor signaling by steric hindrance of $\mathrm{G}$ protein coupling. Moreover, $\beta$-arrestins promote receptor endocytosis (internalization) by recruiting endosomal adaptor proteins. The interaction with $\beta$-arrestin is stabilized by receptor phosphorylation. Seven isoforms of GPCR kinases (GRKs) are responsible for phosphorylating multiple sites of the receptor carboxyl-terminus in response to ligand binding.

In respect to other G proteins, G15 signaling is poorly affected when desensitization is either induced by repeated GPCR activation or it is emphasized by $\beta$-arrestin overexpression (Innamorati et al. 2009). 
G15 is the only Gq/11 family member that does not interact with GRK2, whereas for other G proteins the interaction prompts GRK translocation from the cytosol to the plasma membrane. As a consequence, GRK2 is not recruited to GPCR upstream of G15 (Day et al. 2003). In addition to a reduced receptor phosphorylation, the missing interaction with GRK2 could have additional consequences since the negative modulation that GRK2 exerts on $G$ protein signaling goes beyond its kinase activity. In fact, a kinase-dead GRK2 mutant was reported to equally modulate the activities of Gq, G11, and G14 while leaving the activity of G15 unaffected. GRKs contain regulator of $G$ protein signaling (RGS) domains believed to accelerate $G$ protein inactivation by stabilizing the transition state of $\mathrm{G} \alpha$-catalyzed GTP hydrolysis. It is thus tempting to explain G15 enduring signaling with a prolonged permanence in the GTP bound state. However, the RGS domain of GRK2 was described as particularly weak (Carman et al. 1999), and other GRKs and RGS containing proteins (such as RGS2), known to interact with G15 (Day et al. 2003), could easily compensate. Further investigation is required to explain the mechanistic base of G15 refractoriness to $\beta$-arrestin-dependent desensitization that nevertheless implies the permanence of $\mathrm{G} \alpha 15$ in the complex assembled around the desensitized GPCR. This was shown with a V2 vasopressin receptor mutant constitutively stabilized in a desensitized state by a mutation in the conserved DRY sequence (R137H; Barak et al. 2001). The R137H-V2R coimmunoprecipitated with $\mathrm{G} \alpha 15$, but not with $\mathrm{G} \alpha \mathrm{q}$ or $\mathrm{G} \alpha \mathrm{s}$, as if $\mathrm{G} \alpha 15$ possesses a better capability to remain in direct contact with activated receptors, possibly by competing with $\beta$-arrestin (Innamorati et al. 2009).

The desensitization process modulates GPCR function by adjusting receptor efficiency to the intensity and persistence of the stimulation. In immune cells GRKs and arrestins are dynamically regulated (Vroon et al. 2006) thus the specificity of GPCR response can drastically vary depending on the cell activation state. In the case of stimuli, particularly intense (as possibly during commitment to high proliferation states), G15 could represent a key element that, by better resisting to arrestin-dependent desensitization, takes over when other $\mathrm{G}$ proteins become ineffective. In this model, G15 would determine a qualitative evolution of the signal with the final result of reprogramming the cell.

\section{G15 sensitivity}

The interactions occurring between GPCR and G15 may result in more stablity than the interaction with other $\mathrm{G}$ proteins. A steady interaction of wild-type P2Y2 receptor with $\mathrm{G} \alpha 15$ was assessed by FRET even in the absence of ligand (Kotevic et al. 2005). The presence of G15 biased the pharmacological profile of the $\kappa$ opioid receptor ( $\mathrm{Su}$ et al. 2009), again suggesting the existence of preformed receptor-G protein complexes. A similar interaction with G15 may even interfere with the activation of other $\mathrm{G}$ protein subtypes as shown for pUS28 (Moepps et al. 2008), a viral GPCR characterized by elevated ligand-independent constitutive activity and by increased phosphorylation (Minisini et al. 2003). This effect was unmasked because $\mathrm{Gq} / 11$ promotes serum response factor (SRF)-dependent transcriptional activity much more effectively than G15 or G14, and the overexpression of G15 reduced SRF effect by directly competing with $\mathrm{Gq} / 11$ for the chemokine-activated pUS28 (Moepps et al. 2008).

Exogenous G $\alpha 15$ expression at physiological levels (promoted by a tetracycline-induced transactivation system) exerted a similar effect by blunting the $\mathrm{Ca}^{2+}$ transient induced through the $\mathrm{Gq} / 11$-coupled thyrotropin-releasing hormone receptor (Offermanns et al. 2001). G15 expression also inhibited the signaling of $\beta 2 A R$ to Gs (Innamorati et al. 2009).

Whether the ability of G15 to compete for activated GPCRs relates to its resistance to GPCR desensitization is still to be addressed.

\section{Getting further insights on G15 biological function}

The high degree of promiscuity, combined with the functional redundancy within the $\mathrm{Gq} / 11$ subclass and with the absence of specific pharmacological inhibitors, restricts the number of approaches that can be used to define G15 function. For this reason, many researchers took advantage of G $\alpha 15-\mathrm{Q} 212 \mathrm{~L}$, a constitutively active mutant incapable of efficient GTP hydrolysis. By this approach, direct activation of downstream effectors is achieved bypassing the GPCR. G $\alpha 15-\mathrm{Q} 212 \mathrm{~L}$ promoted the activity of transcription factors like nuclear factor kappa-light-chain-enhancer of activated $\mathrm{B}$ cells $(\mathrm{NF} \kappa \mathrm{B})$ and signal transducer and activator of transcription 3 (STAT3) via PKC (Lo \& Wong 2006, Lee \& Wong 2009) and $\mathrm{c}-\mathrm{Src} / \mathrm{mitogen}$-activated protein kinase (MAPK)dependent pathway (Wu et al. 2003, Liu \& Wong 2004; Fig. 2). As a member of a family of latent cytoplasmic transcription factors, STAT3 has long been implicated in cell growth and development relaying signals from the plasma membrane to the nucleus. It is therefore tempting to speculate that G15 promotes quiescence and initiates differentiation programs in transient amplifying cells. Experiments produced in various cell lines suggested that G15 regulates cell maturation but, at the same time, revealed several contradictory aspects. In a neuronal maturation model (PC12 cells) G15 promoted cell differentiation (Heasley et al. 1996a), and similar results were observed in a model of erythroid differentiation (MB-02 erythroleukemia 


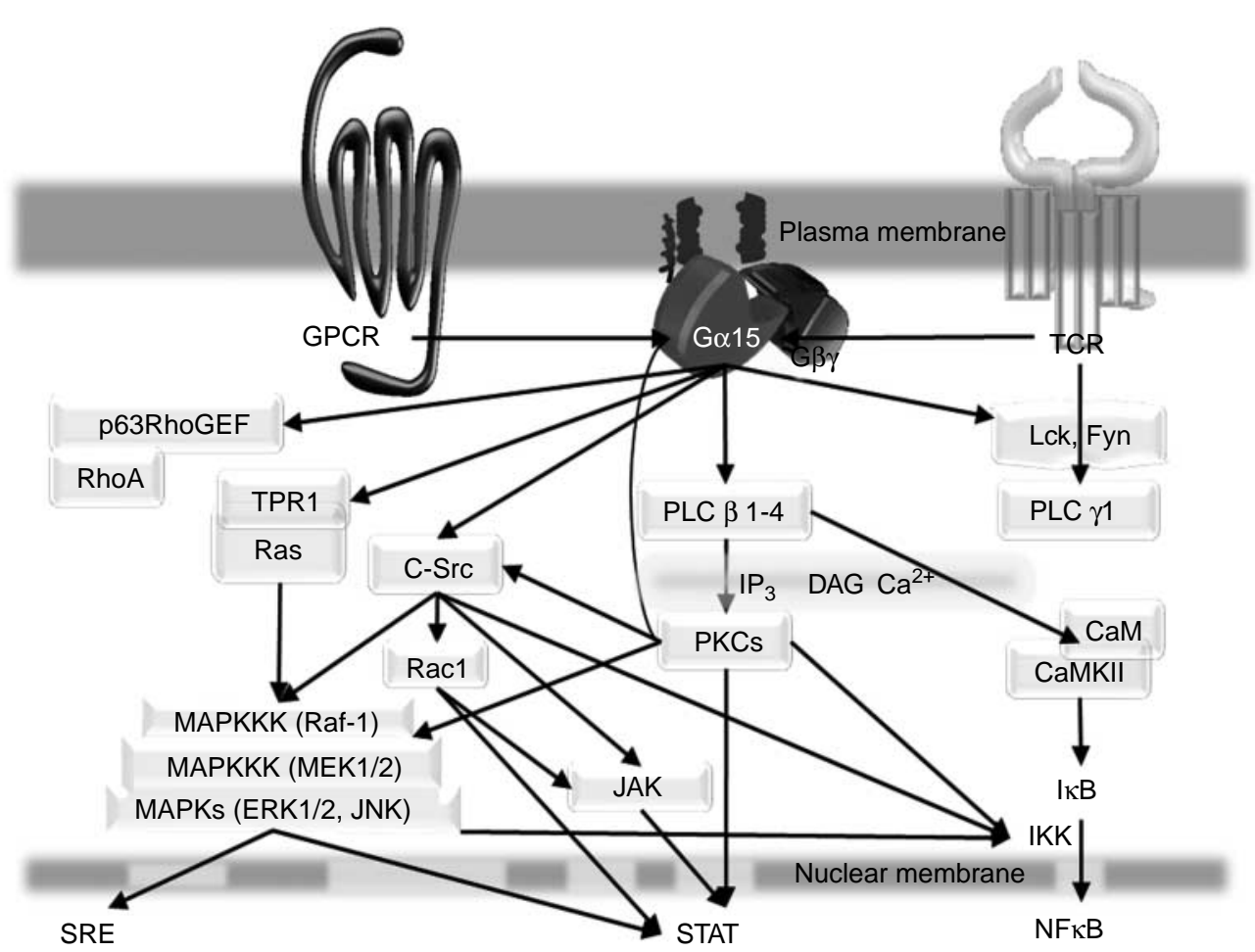

Figure 2 Generalized scheme of G15 signaling. This scheme represents an overlay of signaling pathways that were pointed out by specifically modulating G15 activity. Different approaches were used to achieve this objective including promoting gain of function (by recombinant expression of $\mathrm{G} \alpha 15$ as the wild type form or as a constitutively active mutant) or inducing loss of function in cells endogenously expressing G $\alpha 15$ (by RNA interference or by competing deficient mutant). In many cases, a signaling knot represents more than one protein isoform. Like any other $\mathrm{Gq} / 11$ family member, G15 activates different isoforms of PLC $\beta$ promoting PIP2 hydrolysis in response to GPCR stimulation (Wu et al. 1993, Offermanns \& Simon 1995). The activation of CaMKII (Lo et al. 2003, Liu \& Wong 2004) and $\mathrm{Ca}^{2+}$-dependent (Offermanns et al. 2001) or independent (PKC $\mu$ in COS cells unpublished) PKC isoforms triggers several pathways,

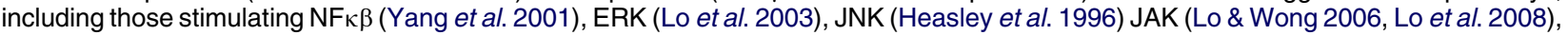
cSrc (Lee et al. 2009). Small GTPases, such as Ras and Rho are indirectly modulated by G15, via TPR1 (Yu et al. 2008, Su et al. 2009) and p63RhoGEF (Yeung \& Wong 2009) respectively. The best characterized effector of Ras is the MAPK pathway that proceeds through ERK1/2 (Fehrenbacher et al. 2009). MAPKs activated by G15 (Buhl et al. 1995, Tian et al. 2008) lead to the activation of transcription factors such as STAT (Lo et al. 2003, Lo \& Wong 2006), NFКB (Yang et al. 2001, Lee \& Wong 2009) and SRE (Mao et al. 1998, Yeung \& Wong 2009). G15 phosphorylation by PKC modulates GPCR coupling providing feedback regulation (Aragay \& Quick 1999, Gu et al. 2003). In addition, like other $\mathrm{Gq} / 11$ family members (Zamoyska 2006), G15 was shown downstream the large signalosoma assembled upon T cell receptor activation (Zhou et al. 1998), G15 was reported as an intermediate effector towards the activation of Lck and Fyn. As a result, the inhibition G15 function reduced lymphocyte activation in response to T cell receptor engagement. In addition, G15 may affect other physiological functions such as transcription, proliferation (Qian et al. 1994), differentiation (Ghose et al. 1999), secretion (Lippert et al. 1997, Offermanns et al. 2001). CaM, calmodulin; CaMKII, CaM kinase II; ERK, extracellular signal-regulated kinases; GPCR, G protein coupled receptor; JAK, janus kinase; JNK, cJun NH2-terminal kinase; Lck, leukocyte-specific protein tyrosine kinase; MAPK, mitogen-activated protein kinases; MAPKK, MAPK kinase; MAPKKK, MAPKK kinase; MEK, MAPK/ERK kinase; p63, Rho GEF p63 Rho G protein exchange factor; PLC, Phospholipase C; PKC, protein kinase C; PIP2, phosphatidylinositol bisphosphate; Rac1, Rasrelated C3 botulinum toxin substrate 1; Raf-1, V-Raf-1 murine leuk. viral oncog. homolog 1; RhoA, Ras homolog gene family, member A; STAT, signal transducers and activators of transcription; TPR1, Tetratricopeptide repeat 1; TCR, T cell receptor.

cells; Ghose et al. 1999). However, in the latter case, overexpression or downmodulation of $\mathrm{G} \alpha 15$ sorted out the same effect. Likewise, in lymphoid Jurkat cells, both sense and antisense DNAs produced a similar reduction in CD69 and IL2 expression (Lippert et al. 1997). Reduced cell growth was obtained in MB-02 and in 'small cell lung carcinoma' (SCLC) cells (Heasley et al. $1996 a)$ upon overexpression of Ga15-Q212L. In vascular smooth muscle cells, only G $\alpha 15$ did not produce pro-apoptotic effects among the $\mathrm{Gq} / 11 \alpha$ family members that were tested (Peavy et al. 2005). In SCLC cell lines, constitutively active G $\alpha 15$ inhibited cloning efficiency, but no effect was observed in 'non-cell lung carcinoma' clones (Heasley et al. 1996a).

Thus, it is far too premature to draw any conclusion. In particular, results based on constitutively active $G \alpha 15$ are particularly questionable because the signal triggered by a permanently active $\mathrm{G} \alpha$-subunit is clearly different from the signal triggered by an activated receptor. First, it does not support transient events, 
such as the acute increase of the intracellular $\mathrm{Ca}^{2+}$ concentration that is normally produced by a receptor. Secondly, signals elicited by constitutively active G proteins lack parallel coordinated pathways initiated by GPCRs that sometimes are even $\mathrm{G}$ protein-independent (Brzostowski \& Kimmel 2001) and, anyway, always include $\beta \gamma$. For example, when G15 is stimulated by the adenosine A1 receptor in HEK cells, the $\beta \gamma$-subunit activates NFкB (Liu \& Wong 2004). Thirdly, the sustained basal inositol phosphate turnover achieved in clones expressing G $\alpha 15-\mathrm{Q} 212 \mathrm{~L}$ produced loss of responsiveness to agonist-dependent $\mathrm{Ca}^{2+}$ mobilization (Heasley et al. 1996a, Lobaugh et al. 1996, Quick et al. 1996), probably due to a partial depletion of $\mathrm{Ca}^{2+}$ stores together with a reduction of inositol trisphosphate receptor number. Exogenous expression of Ga15Q212L inhibited cell growth in NIH-3T3 (Lobaugh et al. 1996) and Swiss 3T3 fibroblasts (Qian et al. 1994), but at the same time inhibited the responsiveness of platelet-derived growth factor (PDGF), ATP, and bombesin towards effectors like PKC, Raf, MEK, thus indicating a general distortion of the signaling network. Finally, cells tonically exposed to $G$ protein signaling might compensate by counteracting downstream signaling steps or even suffer undesired long-term consequences as shown for the same G15 (Lobaugh et al. 1996). Constitutively active $\mathrm{Gq} / 11$ produces PLC $\beta$ signals capable of inducing cell transformation at low levels of expression, but it becomes eventually noxious at higher levels (Kalinec et al. 1992). The type of response to G15 signaling is also likely to depend upon the intensity of the stimulus, and activity levels promoted by overexpression of G $\alpha 15-\mathrm{Q} 212 \mathrm{~L}$ exceed what is normally effective in the cell.

In summary, G15 physiological activity certainly relies on coordinated multibranched signals that are flawed by the chronic activation of a single pathway.

As mentioned above, the assumption that G15 biological role strictly relates to hematopoietic cell growth/differentiation and to lymphocyte activation (Su et al. 2009) is mostly inferred on its distribution and poorly supported by knockout mice that are substantially normal and capable of responding to several inflammatory challenges (Davignon et al. 2000). Normal hematopoiesis was also observed in G $\alpha 15$ and $\mathrm{G} \propto \mathrm{q}$ double knockout mice that in most hematopoietic cells only express $\mathrm{G} \alpha 11$. G $\alpha 11$ knockout mice exhibit as well normal hematopoiesis suggesting functional redundancy in $\mathrm{Gq} / 11$ subclass signaling (Davignon et al. 2000; double G $\alpha$ q and G $\alpha 11$ knockout is lethal). G15 function remains therefore substantially unknown.

G15 activity may become specifically important when GPCR stimulation is particularly intense and prolonged. Under these conditions, desensitization is expected to silence other pathways that are instead more strictly regulated. Retroviral transduction of silencing RNA and conditional knockout models will probably turn out to be determinant in the near future to clarify G15-specific functions: by this mean compensatory mechanisms should be avoided shutting off only G15-dependent branches.

\section{Conclusions}

A number of experimental observations support the hypothesis that G15 appeared late in evolution (Fig. 1C) to fulfill highly specialized functions. A loose selectivity combined to high affinity and atypical resistance to GPCR desensitization could provide a strategy to deliver stimuli that are particularly intense. Such a powerful action is likely to develop along specific intracellular pathways. For instance, only G15 among Gq/11 family members efficiently activates $\mathrm{NF} \kappa \mathrm{B}$ in HeLa cells (in response to fMLP, C5a, C3a, receptors, CCR8, and CXCR2; Yang et al. 2001) and in HEK (in response to adenosine Al receptor; Liu \& Wong 2004). More in general, different genes were transcribed upon transfection of the constitutively active G $\alpha 15$ (Peavy et al. 2005). Unfortunately, thus far, no clear physiological outcome has convincingly been associated to G15 activity.

Treasuring on indications provided by studies in signal transduction, future research will identify circumstances where G15 atypical signaling is matched by evident phenotypic outcomes. G15 is expressed in tissues characterized by a high rate of cell turnover (bone marrow and epithelia (Lippert et al. 1997)). We suggest that research focus should be extended beyond the immune response (epithelial and other intermediate maturation stages) and that experimental conditions should highlight G15 function peculiarities so that its effects emerge over the redundant functions of the other $\mathrm{Gq}$ family members (i.e. under prolonged/ intense GPCR stimulations).

\section{Declaration of interest}

The authors declare that there is no conflict of interest that could be perceived as prejudicing the impartiality of the research reported.

\section{Funding}

This work was partially supported by grants from Fondazione Cariverona (Progetti Bando 2007), University of Verona ('Joint project 2007') by ABO-Project to M Colombatti and from the Italian Ministry of University and Research (MiUR) (FIRB grant no. RBIN04CKYN) to M Parenti. 


\section{Acknowledgements}

We wish to thank Dr Aldo Scarpa for helpful advice and for providing some of the reagents utilized in Fig. 1A, and we also thank Dr Antonella Ronchi for sharing information about $\mathrm{G} \alpha 15$ distribution in microarrays.

\section{References}

Amatruda TT III, Steele DA, Slepak VZ \& Simon MI 1991 G $\propto 16$, a G protein $\alpha$ subunit specifically expressed in hematopoietic cells. PNAS 88 5587-5591.

Amatruda TT III, Gerard NP, Gerard C \& Simon MI 1993 Specific interactions of chemoattractant factor receptors with G-proteins. Journal of Biological Chemistry 268 10139-10144.

Aragay AM \& Quick MW 1999 Functional regulation of $\mathrm{G} \alpha 16$ by protein kinase C. Journal of Biological Chemistry 274 4807-4815.

Arai H \& Charo IF 1996 Differential regulation of G-protein-mediated signaling by chemokine receptors. Journal of Biological Chemistry 271 21814-21819.

Baltensperger K \& Porzig H 1997 The P2U purinoceptor obligatorily engages the heterotrimeric G protein G16 to mobilize intracellular $\mathrm{Ca}^{2+}$ in human erythroleukemia cells. Journal of Biological Chemistry 272 10151-10159.

Barak LS, Oakley RH, Laporte SA \& Caron MG 2001 Constitutive arrestin-mediated desensitization of a human vasopressin receptor mutant associated with nephrogenic diabetes insipidus. PNAS 98 93-98.

Bruges G, Borges A, Sanchez de Villarroel S, Lippo de Bécemberg I, Francis de Toba G, Pláceres F, González de Alfonzo R \& Alfonzo M] 2007 Coupling of M3 acetylcholine receptor to Gq16 activates a natriuretic peptide receptor guanylyl cyclase. Journal of Receptor and Signal Transduction Research 27 189-216.

Brzostowski JA \& Kimmel AR 2001 Signaling at zero G: G-proteinindependent functions for 7-TM receptors. Trends in Biochemical Sciences 26 291-297.

Buhl AM, Osawa S \& Johnson GL 1995 Mitogen-activated protein kinase activation requires two signal inputs from the human anaphylatoxin C5a receptor. Journal of Biological Chemistry $\mathbf{2 7 0}$ 19828-19832.

Carman CV, Parent JL, Day PW, Pronin AN, Sternweis PM, Wedegaertner PB, Gilman AG, Benovic JL \& Kozasa T 1999 Selective regulation of $\mathrm{G} \alpha(\mathrm{q} / 11)$ by an RGS domain in the $\mathrm{G}$ protein-coupled receptor kinase, GRK2. Journal of Biological Chemistry 274 34483-34492.

Clark RA, Yamanaka K, Bai M, Dowgiert R \& Kupper TS 2005 Human skin cells support thymus-independent T cell development. Journal of Clinical Investigation 115 3239-3249.

Contos JJ, Ye X, Sah VP \& Chun J 2002 Tandem genomic arrangement of a $\mathrm{G}$ protein (Gna15) and $\mathrm{G}$ protein-coupled receptor $(\mathrm{s} 1 \mathrm{p}(4) / \operatorname{lp}(\mathrm{C1}) / \mathrm{Edg} 6)$ gene. FEBS Letters 531 99-102.

Davignon I, Catalina MD, Smith D, Montgomery J, Swantek J, Croy J, Siegelman M \& Wilkie TM 2000 Normal hematopoiesis and inflammatory responses despite discrete signaling defects in $\mathrm{G} \alpha 15$ knockout mice. Molecular and Cellular Biology 20 797-804.

Day PW, Carman CV, Sterne-Marr R, Benovic JL \& Wedegaertner PB 2003 Differential interaction of GRK2 with members of the G $\alpha q$ family. Biochemistry 42 9176-9184.

den Dekker E, Gorter G, van der Vuurst H, Heemskerk JW \& Akkerman JW 2001 $a$ Biogenesis of G-protein mediated calcium signaling in human megakaryocytes. Thrombosis and Haemostasis 86 1106-1113.

den Dekker E, Molin DG, Breikers G, van Oerle R, Akkerman JW, van Eys GJ \& Heemskerk JW $2001 b$ Expression of transient receptor potential mRNA isoforms and $\mathrm{Ca}(2+)$ influx in differentiating human stem cells and platelets. Biochimica et Biophysica Acta 1539 243-255.

Dereeper A, Guignon V, Blanc G, Audic S, Buffet S, Chevenet F, Dufayard JF, Guindon S, Lefort V, Lescot M et al. 2008 Phylogeny.fr: robust phylogenetic analysis for the non-specialist. Nucleic Acids Research 36 W465-W469.

DeWire SM, Ahn S, Lefkowitz RJ \& Shenoy SK 2007 Beta-arrestins and cell signaling. Annual Review of Physiology 69 483-510.

Fehrenbacher N, Bar-Sagi D \& Philips M 2009 Ras/MAPK signaling from endomembranes. Molecular Oncology 3 297-307.

Ghose S, Porzig H \& Baltensperger K 1999 Induction of erythroid differentiation by altered $\mathrm{G} \alpha 16$ activity as detected by a reporter gene assay in MB-02 cells. Journal of Biological Chemistry 274 12848-12854.

Giesberts AN, van Ginneken M, Gorter G, Lapetina EG, Akkerman JW \& van Willigen G 1997 Subcellular localization of $\alpha$-subunits of trimeric G-proteins in human platelets. Biochemical and Biophysical Research Communications 234 439-444.

Gilliam AC, Kremer IB, Yoshida Y, Stevens SR, Tootell E, Teunissen MB, Hammerberg C \& Cooper KD 1998 The human hair follicle: a reservoir of $\mathrm{CD} 40+\mathrm{B} 7$-deficient Langerhans cells that repopulate epidermis after UVB exposure. Journal of Investigative Dermatology 110 422-427.

Graler MH, Grosse R, Kusch A, Kremmer E, Gudermann T \& Lipp M 2003 The sphingosine 1-phosphate receptor S1P4 regulates cell shape and motility via coupling to Gi and G12/13. Journal of Cellular Biochemistry 89 507-519.

Grant KR, Harnett W, Milligan G \& Harnett MM 1997 Differential G-protein expression during B- and T-cell development. Immunology $90564-571$.

Gu JL, Lu W, Xia C, Wu X \& Liu M 2003 Regulation of hematopoieticspecific G-protein $\mathrm{G} \alpha 15$ and $\mathrm{G} \alpha 16$ by protein kinase C. Journal of Cellular Biochemistry 88 1101-1111.

Gutierrez-Frias C, Sacedon R, Hernandez-Lopez C, Cejalvo T, Crompton T, Zapata AG, Varas A \& Vicente A 2004 Sonic hedgehog regulates early human thymocyte differentiation by counteracting the IL-7-induced development of CD34+ precursor cells. Journal of Immunology 173 5046-5053.

Hakak Y, Shrestha D, Goegel MC, Behan DP \& Chalmers DT 2003 Global analysis of G-protein-coupled receptor signaling in human tissues. FEBS Letters $\mathbf{5 5 0} 11-17$.

Heasley LE, Storey B, Fanger GR, Butterfield L, Zamarripa J, Blumberg D \& Maue RA 1996 $a$ GTPase-deficient $\mathrm{G} \alpha 16$ and G $\alpha$ q induce PC12 cell differentiation and persistent activation of cJun NH2-terminal kinases. Molecular and Cellular Biology 16 648-656.

Heasley LE, Zamarripa J, Storey B, Helfrich B, Mitchell FM, Bunn PA Jr \& Johnson GL 1996b Discordant signal transduction and growth inhibition of small cell lung carcinomas induced by expression of GTPase-deficient Ga16. Journal of Biological Chemistry 271 349-354.

Hubbard KB \& Hepler JR 2006 Cell signalling diversity of the Gq $\alpha$ family of heterotrimeric G proteins. Cellular Signalling 18 135-150.

Innamorati G, Piccirillo R, Bagnato P, Palmisano I \& Schiaffino MV 2006 The melanosomal/lysosomal protein OAl has properties of a G protein-coupled receptor. Pigment Cell Research 19 125-135.

Innamorati G, Giannone F, Guzzi F, Rovati GE, Accomazzo MR, Chini B, Bianchi E, Schiaffino MV, Tridente G \& Parenti M 2009 Heterotrimeric $\mathrm{G}$ proteins demonstrate differential sensitivity to beta-arrestin dependent desensitization. Cellular Signalling 21 $1135-1142$.

Kahn AB, Ryan MC, Liu H, Zeeberg BR, Jamison DC \& Weinstein JN 2007 SpliceMiner: a high-throughput database implementation of the NCBI Evidence Viewer for microarray splice variant analysis. BMC Bioinformatics 875.

Kalinec G, Nazarali AJ, Hermouet S, Xu N \& Gutkind JS 1992 Mutated $\alpha$ subunit of the Gq protein induces malignant transformation in NIH 3T3 cells. Molecular and Cellular Biology 12 4687-4693. 
Kleuss C, Scherubl H, Hescheler J, Schultz G \& Wittig B 1993 Selectivity in signal transduction determined by gamma subunits of heterotrimeric G proteins. Science 259 832-834.

Kotevic I, Kirschner KM, Porzig H \& Baltensperger K 2005 Constitutive interaction of the $\mathrm{P} 2 \mathrm{Y} 2$ receptor with the hematopoietic cell-specific $\mathrm{G}$ protein $\mathrm{G}(\alpha 16)$ and evidence for receptor oligomers. Cellular Signalling 17 869-880.

Krumins AM \& Gilman AG 2006 Targeted knockdown of G protein subunits selectively prevents receptor-mediated modulation of effectors and reveals complex changes in non-targeted signaling proteins. Journal of Biological Chemistry 281 10250-10262.

Kuang Y, Wu Y, Jiang H \& Wu D 1996 Selective G protein coupling by $\mathrm{C}-\mathrm{C}$ chemokine receptors. Journal of Biological Chemistry 271 3975-3978.

Kumamoto T, Shalhevet D, Matsue H, Mummert ME, Ward BR, Jester JV \& Takashima A 2003 Hair follicles serve as local reservoirs of skin mast cell precursors. Blood 102 1654-1660.

Kusakabe Y, Yamaguchi E, Tanemura K, Kameyama K, Chiba N, Arai S, Emori Y \& Abe K 1998 Identification of two $\alpha$-subunit species of GTP-binding proteins, $\mathrm{G} \alpha 15$ and $\mathrm{G} \alpha \mathrm{q}$, expressed in rat taste buds. Biochimica et Biophysica Acta 1403 265-272.

Lai JP, Yang JH, Douglas SD, Wang X, Riedel E \& Ho WZ 2003 Quantification of CCR5 mRNA in human lymphocytes and macrophages by real-time reverse transcriptase PCR assay. Clinical and Diagnostic Laboratory Immunology 10 1123-1128.

Lee MM \& Wong YH 2009 CCR1-mediated activation of nuclear factor$\{k a p p a\} B$ in THP-1 monocytic cells involves pertussis toxininsensitive $\mathrm{G} \alpha 14$ and $\mathrm{G} \alpha 16$ signaling cascades. Journal of Leukocyte Biology 86 1319-1329.

Lee JW, Joshi S, Chan JS \& Wong YH 1998 Differential coupling of mu-, delta-, and kappa-opioid receptors to $\mathrm{G} \alpha 16$-mediated stimulation of phospholipase C. Journal of Neurochemistry 70 2203-2211.

Levesque JP \& Winkler IG 2008 Mobilization of hematopoietic stem cells: state of the art. Current Opinion in Organ Transplantation $1353-58$.

Lippert E, Baltensperger K, Jacques Y \& Hermouet S 1997 G $\alpha 16$ protein expression is up- and down-regulated following T-cell activation: disruption of this regulation impairs activation-induced cell responses. FEBS Letters 417 292-296.

Liu AM \& Wong YH 2004 G16-mediated activation of nuclear factor kappaB by the adenosine A1 receptor involves c-Src, protein kinase C, and ERK signaling. Journal of Biological Chemistry $\mathbf{2 7 9}$ 53196-53204.

Lo RK \& Wong YH 2006 Transcriptional activation of c-Fos by constitutively active $\mathrm{G} \alpha(16) \mathrm{QL}$ through a STAT1-dependent pathway. Cellular Signalling 18 2143-2153.

Lo RK, Cheung H \& Wong YH 2003 Constitutively active G $\alpha 16$ stimulates STAT3 via a c-Src/JAK- and ERK-dependent mechanism. Journal of Biological Chemistry 278 52154-52165.

Lo RK, Liu AM, Wise H \& Wong YH 2008 Prostacyclin receptorinduced STAT3 phosphorylation in human erythroleukemia cells is mediated via $\mathrm{G} \alpha$ s and $\mathrm{G} \alpha 16$ hybrid signaling. Cellular Signalling 20 2095-2106.

Lobaugh LA, Eisfelder B, Gibson K, Johnson GL \& Putney JW Jr 1996 Constitutive activation of a phosphoinositidase C-linked $\mathrm{G}$ protein in murine fibroblasts decreases agonist-stimulated $\mathrm{Ca}^{2+}$ mobilization. Molecular Pharmacology 50 493-500.

Luthin GR, Wang P, Zhou H, Dhanasekaran D \& Ruggieri MR 1997 Role of $\mathrm{m} 1$ receptor-G protein coupling in cell proliferation in the prostate. Life Sciences 60 963-968.

Maggio R, Innamorati G \& Parenti M 2007 G protein-coupled receptor oligomerization provides the framework for signal discrimination. Journal of Neurochemistry 103 1741-1752.

Mao J, Yuan H, Xie W, Simon MI \& Wu D 1998 Specific involvement of $\mathrm{G}$ proteins in regulation of serum response factor-mediated gene transcription by different receptors. Journal of Biological Chemistry 273 27118-27123.
Mapara MY, Bommert K, Bargou RC, Leng C, Beck C, Ludwig WD, Gierschik P \& Dorken B 1995 G protein subunit G $\alpha 16$ expression is restricted to progenitor $\mathrm{B}$ cells during human B-cell differentiation. Blood 85 1836-1842.

Masdeu C, Faure H, Coulombe J, Schoenfelder A, Mann A, Brabet I, Pin JP, Traiffort E \& Ruat M 2006 Identification and characterization of Hedgehog modulator properties after functional coupling of smoothened to G15. Biochemical and Biophysical Research Communications 349 471-479.

Milligan G, Marshall F \& Rees S 1996 G16 as a universal G protein adapter: implications for agonist screening strategies. Trends in Pharmacological Sciences 17 235-237.

Minisini R, Tulone C, Luske A, Michel D, Mertens T, Gierschik P \& Moepps B 2003 Constitutive inositol phosphate formation in cytomegalovirus-infected human fibroblasts is due to expression of the chemokine receptor homologue pUS28. Journal of Virology 77 4489-4501.

Moepps B, Tulone C, Kern C, Minisini R, Michels G, Vatter P, Wieland T \& Gierschik P 2008 Constitutive serum response factor activation by the viral chemokine receptor homologue pUS28 is differentially regulated by $\mathrm{G} \alpha(\mathrm{q} / 11)$ and $\mathrm{G} \alpha(16)$. Cellular Signalling 20 $1528-1537$.

Muthu K, Iyer S, He LK, Szilagyi A, Gamelli RL, Shankar R \& Jones SB 2007 Murine hematopoietic stem cells and progenitors express adrenergic receptors. Journal of Neuroimmunology 186 27-36.

Offermanns S \& Simon MI $1995 \mathrm{G} \alpha 15$ and G $\alpha 16$ couple a wide variety of receptors to phospholipase C. Journal of Biological Chemistry $\mathbf{2 7 0}$ 15175-15180.

Offermanns S, Negulescu P, Hu YH \& Simon MI 2001 Conditionally expressed $\mathrm{G} \alpha 15$ couples to endogenous receptors in GH3 cells. Naunyn-Schmiedeberg's Archives of Pharmacology 364 140-148.

Ostrom RS \& Insel PA 2004 The evolving role of lipid rafts and caveolae in $\mathrm{G}$ protein-coupled receptor signaling: implications for molecular pharmacology. British Journal of Pharmacology 143 235-245.

Peavy RD, Hubbard KB, Lau A, Fields RB, Xu K, Lee CJ, Lee TT, Gernert K, Murphy TJ \& Hepler JR 2005 Differential effects of $\mathrm{Gq} \alpha, \mathrm{G} 14 \alpha$, and $\mathrm{G} 15 \alpha$ on vascular smooth muscle cell survival and gene expression profiles. Molecular Pharmacology 67 2102-2114.

Pedone KH \& Hepler JR 2007 The importance of N-terminal polycysteine and polybasic sequences for G14 $\alpha$ and G16 $\alpha$ palmitoylation, plasma membrane localization, and signaling function. Journal of Biological Chemistry 282 25199-25212.

Pfeilstöcker M, Karlic H, Salamon J, Mühlberger H, Pavlova B, Selim U, Strobl H, Pittermann E \& Heinz R 1998 Monitoring of hematopoietic recovery after autologous stem cell transplantation by analysis of G $\alpha 16$ mRNA and CD34 surface glycoprotein. Annals of Hematology 76 153-158.

Pfeilstocker M, Karlic H, Salamon J, Muhlberger H, Pavlova B, Strobl H, Pittermann E \& Heinz R 2000 Hematopoietic recovery after IEV chemotherapy for malignant lymphoma followed by different cytokines can be monitored by analysis of $\mathrm{G} \alpha 16$ and CD34. American Journal of Hematology 64 156-160.

Qian NX, Russell M, Buhl AM \& Johnson GL 1994 Expression of GTPase-deficient G $\alpha 16$ inhibits Swiss 3T3 cell growth. Journal of Biological Chemistry 269 17417-17423.

Quick MW, Lester HA, Davidson N, Simon MI \& Aragay AM 1996 Desensitization of inositol 1,4,5-trisphosphate $/ \mathrm{Ca}^{2+}$-induced $\mathrm{Cl}^{-}$ currents by prolonged activation of $\mathrm{G}$ proteins in Xenopus oocytes. Journal of Biological Chemistry 271 32021-32027.

Rivera J, Proia RL \& Olivera A 2008 The alliance of sphingosine-1phosphate and its receptors in immunity. Nature Reviews. Immunology 8 753-763. 
Robillard L, Ethier N, Lachance M \& Hebert TE 2000 Gbetagamma subunit combinations differentially modulate receptor and effector coupling in vivo. Cellular Signalling 12 673-682.

Robishaw JD, Smigel MD \& Gilman AG 1986 Molecular basis for two forms of the $\mathrm{G}$ protein that stimulates adenylate cyclase. Journal of Biological Chemistry 261 9587-9590.

Rock BM, Xin L \& Wilcox JN 1997 Two Gq class G proteins are expressed in human keratinocytes. Journal of Investigative Dermatology 109 645-649.

Rozenfeld-Granot G, Toren A, Amariglio N, Nagler A, Rosenthal E, Biniaminov M, Brok-Simoni F \& Rechavi G 2002 MAP kinase activation by mu opioid receptor in cord blood CD34 (+ ) CD38 ( - ) cells. Experimental Hematology 30 473-480.

Ruggieri MR, Colton MD, Wang P, Wang J, Smyth RJ, Pontari MA \& Luthin GR 1995 Human prostate muscarinic receptor subtypes. Journal of Pharmacology and Experimental Therapeutics 274 976-982.

Schmidt M, Evellin S, Weernink PA, von Dorp F, Rehmann H, Lomasney JW \& Jakobs KH 2001 A new phospholipase-C-calcium signalling pathway mediated by cyclic AMP and a Rap GTPase. Nature Cell Biology 3 1020-1024.

Shi C, Mai Y \& Cheng T 2003 Identification of hematopoietic cell populations from the dermal papillae of human hair follicles. Transplantation Proceedings 36 3208-3211.

Su Y, Ho MK \& Wong YH 2009 A hematopoietic perspective on the promiscuity and specificity of G $\alpha 16$ signaling. Neurosignals 17 71-81.

Tenailleau S, Corre I \& Hermouet S 1997 Specific expression of heterotrimeric G proteins G12 and G16 during human myeloid differentiation. Experimental Hematology 25 927-934.

Tian Y, Lee MM, Yung LY, Allen RA, Slocombe PM, Twomey BM \& Wong YH 2008 Differential involvement of G $\alpha 16$ in CC chemokineinduced stimulation of phospholipase Cbeta, ERK, and chemotaxis. Cellular Signalling 20 1179-1189.

Trempus CS, Morris RJ, Bortner CD, Cotsarelis G, Faircloth RS, Reece JM \& Tennant RW 2003 Enrichment for living murine keratinocytes from the hair follicle bulge with the cell surface marker CD34. Journal of Investigative Dermatology 120 501-511.

Tsukamoto T, Toyama R, Itoh H, Kozasa T, Matsuoka M \& Kaziro Y 1991 Structure of the human gene and two rat cDNAs encoding the $\alpha$ chain of GTP-binding regulatory protein Go: two different mRNAs are generated by alternative splicing. PNAS 88 2974-2978.

Vroon A, Heijnen CJ \& Kavelaars A 2006 GRKs and arrestins: regulators of migration and inflammation. Journal of Leukocyte Biology 80 1214-1221.
Wilkie TM, Scherle PA, Strathmann MP, Slepak VZ \& Simon MI 1991 Characterization of G-protein $\alpha$ subunits in the Gq class: expression in murine tissues and in stromal and hematopoietic cell lines. PNAS 88 10049-10053.

Wu D, LaRosa GJ \& Simon MI 1993 G protein-coupled signal transduction pathways for interleukin-8. Science 261 101-103.

Wu D, Kuang Y, Wu Y \& Jiang H 1995 Selective coupling of beta 2-adrenergic receptor to hematopoietic-specific $\mathrm{G}$ proteins. Journal of Biological Chemistry 270 16008-16010.

Wu EH, Lo RK \& Wong YH 2003 Regulation of STAT3 activity by G16-coupled receptors. Biochemical and Biophysical Research Communications $\mathbf{3 0 3}$ 920-925.

Yan X \& Owens DM 2008 The skin: a home to multiple classes of epithelial progenitor cells. Stem Cell Reviews 4 113-118.

Yang M, Sang H, Rahman A, Wu D, Malik AB \& Ye RD 2001 G $\alpha 16$ couples chemoattractant receptors to NF- $\mathrm{B}$ activation. Journal of Immunology 166 6885-6892.

Yatomi Y, Ozaki Y, Ohmori T \& Igarashi Y 2001 Sphingosine 1-phosphate: synthesis and release. Prostaglandins $\mathcal{E}^{\circ}$ Other Lipid Mediators 64 107-122.

Yeung WW \& Wong YH 2009 The RhoA-specific guanine nucleotide exchange factor p63RhoGEF binds to activated $\mathrm{G} \alpha(16)$ and inhibits the canonical phospholipase Cbeta pathway. Cellular Signalling $\mathbf{2 1}$ 1317-1325.

Yu MY, Ho MK, Liu AM \& Wong YH 2008 Mutations on the Switch III region and the $\alpha 3$ helix of $\mathrm{G} \alpha 16$ differentially affect receptor coupling and regulation of downstream effectors. Journal of Molecular Signaling 317.

Zamoyska R 2006 Superantigens: supersignalers? Science's STKE 358 pe 45.

Zhou J, Stanners J, Kabouridis P, Han H \& Tsoukas CD 1998 Inhibition of TCR/CD3-mediated signaling by a mutant of the hematopoietically expressed G16 GTP-binding protein. European Journal of Immunology 28 1645-1655.

Zhu X \& Birnbaumer L 1996 G protein subunits and the stimulation of phospholipase $\mathrm{C}$ by Gs-and Gi-coupled receptors: lack of receptor selectivity of $\mathrm{G} \alpha(16)$ and evidence for a synergic interaction between Gbeta gamma and the $\alpha$ subunit of a receptor activated $\mathrm{G}$ protein. PNAS 93 2827-2831.

Received in final form 23 January 2010

Accepted 11 February 2010

Made available online as an Accepted Preprint

11 February 2010 